\title{
Ischaemic spinal cord injury after cardiac surgery
}

\author{
J W L PUNTIS AND S H GREEN
}

Department of Paediatrics and Child Health, University of Birmingham

SUMMARY The case records of eight children with an acute spinal cord lesion after cardiac surgery were reviewed. All had been operated on for congenital heart disease over the past 10 years. The prognosis for neurological recovery was poor and scoliosis and bladder dysfunction were common complications. Ischaemic cord injury is usually associated with coarctation of the aorta but may occur when surgery is performed for other cardiovascular defects.

Spinal cord infarction in children is rare but may occur in association with heart disease. In 1889 , Gowers reported such a case ${ }^{1}$ in a 16 year old boy with bacterial endocarditis and suggested an embolic aetiology. Although a number of surgical reviews have examined the incidence of cord injury in adults undergoing resection of coarctation of the aorta, references to children with cardiovascular disease developing paraparesis are rare. We were therefore prompted by a recent case to examine our experience of this problem over the past 10 years. Eight cases were identified all of whom had been operated on for cardiac lesions. There were four boys and four girls affected at ages ranging from 8 months to 15 years and now followed up for a mean period of four years.

\section{Clinical manifestations}

Clinical presentation was exemplified by that of a 12 year old girl who underwent repair of ventricular and atrial septal defects on cardiopulmonary bypass with hypothermia. The following day she did not respond to the discomfort of intramuscular injection and she could not move her legs. Examination showed normal upper limb and abdominal reflexes but absent lower limb reflexes. She had no perception of pain and temperature in her legs and a sensory level at T11. Proprioception and vibration sense were preserved. She had a distended bladder which she was unable to empty. Sensation began to recover after several days but three months after the operation she requires leg calipers for walking.

All the patients presented in a similar manner. The cardiac condition leading to surgery and factors that may have contributed to cord injury are described for each patient in Table 1: long term complications seen during follow up are given in Table 2.

Table 1 Operative procedure and factors that may have contributed to spinal cord injury

\begin{tabular}{|c|c|c|c|c|}
\hline Case no & Sex & $\begin{array}{l}\text { Age at } \\
\text { operation } \\
\text { (years) }\end{array}$ & Operation & Risk factors for cord damage \\
\hline 2 & $\mathbf{F}$ & 0.7 & $\begin{array}{l}\text { Closure of VSD and debanding of pulmonary } \\
\text { artery on bypass }\end{array}$ & None apparent \\
\hline 3 & $\mathbf{F}$ & 2 & Resection of coarctation of aorta & $\begin{array}{l}\text { (1) Coarctation } \\
\text { (2) Intraoperative cardiac arrest } \\
\text { (3) Previous heart surgery }\end{array}$ \\
\hline 4 & $\mathbf{F}$ & 3 & Total correction of Fallot's tetralogy on bypass & Low output failure postoperatively \\
\hline 5 & $\mathbf{M}$ & 3 & Resection of coarctation of aorta & $\begin{array}{l}\text { (1) Coarctation } \\
\text { (2) Second resection } \\
\text { (3) Intraoperative cardiac arrest }\end{array}$ \\
\hline 6 & $\mathbf{M}$ & 6 & Ligation of patent ductus arteriosus & Clamping of aorta for emergency haemostasis \\
\hline 7 & $\mathbf{M}$ & 6 & Blalock shunt (single ventricle) & Clamping of aorta for haemostasis \\
\hline 8 & $\mathbf{M}$ & 15 & Resection of coarctation of aorta & $\begin{array}{l}\text { (1) Coarctation } \\
\text { (2) Postoperative haemorrhage and hypotension }\end{array}$ \\
\hline
\end{tabular}

$\mathrm{VSD}=$ ventricular septal defect; $\mathrm{ASD}=$ atrial septal defect. 
Table 2 Spinal cord damage: late complications seen during follow up

\begin{tabular}{|c|c|}
\hline $\begin{array}{l}\text { Case } \\
\text { no }\end{array}$ & Complications \\
\hline 1 & Considerable paraparesis; requires aids for mobility. \\
\hline 2 & $\begin{array}{l}\text { Considerable paraparesis; requires aids for mobility. Bilateral } \\
\text { dislocation of hips; operative reduction. Recurrent urinary tract } \\
\text { infections; reimplantation of ureters for vesico-ureteric reflux. }\end{array}$ \\
\hline 3 & $\begin{array}{l}\text { Considerable paraparesis; requires aids for mobility. Recurrent } \\
\text { urinary tract infection; urge incontinence. Lumbar scoliosis. } \\
\text { Elongation of tendo-Achilles operation. }\end{array}$ \\
\hline 4 & Minimal leg weakness and slight increase in muscle tone. \\
\hline 5 & $\begin{array}{l}\text { Considerable paraparesis; requires aids for mobility. Lumbar } \\
\text { lordosis; bilateral psoas release operations. Attends school for } \\
\text { physically handicapped. Reflux nephropathy; hypertension. }\end{array}$ \\
\hline 6 & $\begin{array}{l}\text { Considerable paraparesis; requires aids for mobility. Spastic bladder; } \\
\text { recurrent urinary tract infection. }\end{array}$ \\
\hline 7 & $\begin{array}{l}\text { Considerable paraparesis; requires aids for mobility. Severe scoliosis; } \\
\text { spinal fusion. Elongation of tendo-Achilles operation. Dislocation } \\
\text { of hips; femoral osteotomies. }\end{array}$ \\
\hline 8 & Considerable paraparesis; wheelchair for mobility. \\
\hline
\end{tabular}

\section{Discussion}

Neurological complications of congenital heart disease are well documented, ${ }^{2}{ }^{3}$ and paraplegia complicating coarctation of the aorta in both adults and children has been described. The overall incidence of spinal cord damage in resection of aortic coarctation is around $0.4 \%,{ }^{4}$ and although this is most commonly related to surgery, it may on occasions be spontaneous. One of us (SHG) has seen cord infarction in a boy who presented with acute interscapular pain and was subsequently found to have coarctation. This particular symptom is described in adults with cord infarction from other causes. ${ }^{5}$ In spontaneous cord infarction associated with coarctation, the lesion probably arises as a result of pressure on the cord from either an aneurysmal dilatation of an intercostal artery collateral, or bleeding giving rise to a haematoma.

An understanding of the blood supply to the spinal cord is necessary to appreciate how ischaemia may occur. The embryonal spinal cord is supplied by a series of segmental vessels which later in development undergo extensive modification and an anastamotic network running vertically on both anterior and posterior aspects of the cord is formed. The anterior two thirds of the cord receives blood from penetrating branches of the anterior channel while the posterior one third is fed by branches of the posterior channel (Fig. 1).

These anastamosing channels constitute the anterior and posterior spinal arteries and depend heavily for the blood supply on the variable remaining segmental vessels (Fig. 2). The most consistent of

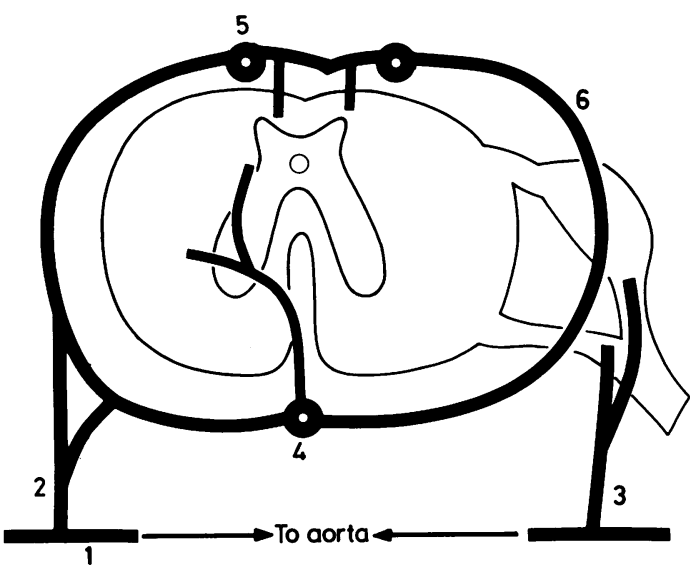

Fig. 1 Cross section of the spinal cord and arterial blood supply.

(1) Intercostal artery

(2) Posterior branch supplying cord (eg great artery of Adamciewicz)

(3) Posterior branch supplying nerve roots only (usual pattern).

(4) Anterior spinal artery.

(5) Posterior spinal artery.

(6) Circumflex vessel supplying surface of cord

these is a branch of the costocervical trunk in the lower cervical region and the great artery of Adamciewicz; this vessel arises from an intercostal artery usually at the level of the diaphragm and on the left side, although it is variable in size and position. It is more or less alone in supplying the lower thoracic and upper lumbar regions of the cord. The anterior and posterior spinal arteries are not therefore continuous and discrete structures but rather variable anastamotic networks, inefficient in places so that areas of cord between segmental vessels are at risk from ischaemic injury should perfusion be disturbed by surgery, hypotension, or embolism.

The acute anterior horn cell disorder with sensory level in the lower thoracic region seen in our patients may be explained by ischaemia in the region of the great artery of Adamciewicz. Preservation of posterior column sensation suggests blood flow in the posterior spinal artery is relatively less affected. Cross clamping of the aorta for haemostasis leading to a reduced distal perfusion is the obvious aetiological factor in two of our patients (cases 6 and 7). Despite the fact that in coarctation of the aorta collateral vessels develop distal to the narrowed segment, blood flow through them during surgery once the aorta is cross clamped may not be adequate (cases 3 and 5). In two patients, operations for ventricular septal defect repair were uncomplicated, yet cord damage was later seen (cases 1 and 2 ). 


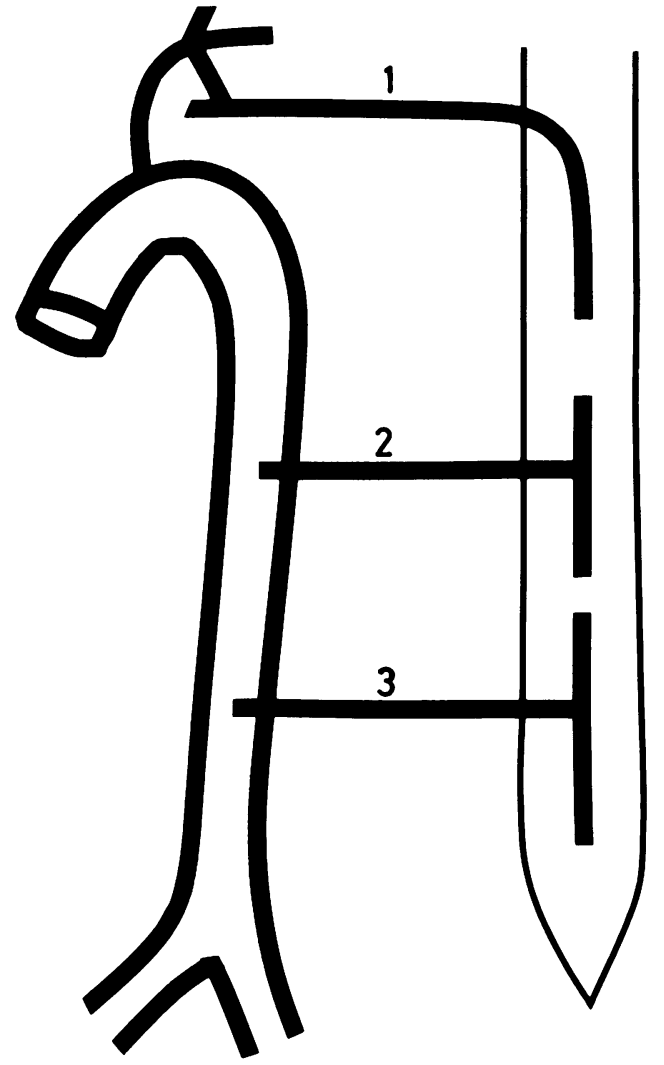

Fig. 2 Arterial supply to the spinal cord.

(1) Branch of costocervical trunk supplies lower cervical region.

(2) Mid-thoracic cord usually supplied by a single intercostal vessel.

(3) Thoracolumbar region supplied by great artery of Adamciewicz.

Although continuous blood pressure monitoring showed systemic pressure to be well maintained, local hypoperfusion cannot be excluded; bypass techniques generate microemboli which have been implicated in encephalopathic states after operation, ${ }^{67}$ and this may be an aetiological factor in otherwise unexplained cord damage. In case 8, postoperative bleeding and hypotension led to ischaemia.

An awareness among cardiothoracic surgeons that spinal cord damage may occur during operation for resection of coarctation of the aorta led to consideration of how the risk of this complication could be assessed for each individual patient and also how damage might be prevented. Subjective clinical signs such as preoperative femoral pulse amplitude, the blood pressure difference between upper and lower limbs, collateral bruits or the size of collateral vessels at thoracotomy have proved unsatisfactory as guides to the safety of the cord during aortic occlusion. Hypothermia and the grafting of conduits to bypass the coarctation have been advocated, together with left heart bypass, for their protective effects by maintaining distal perfusion. ${ }^{4}$ More recently the need for an objective assessment of risk to the cord has been emphasised. ${ }^{8}$ This may be achieved by measuring intra-aortic pressure distal to the coarctation both at the start of the operation and after the aortic clamp is applied. If the distal pressure falls below $50 \mathrm{~mm} \mathrm{Hg}$ after application of the clamp, left atrial-femoral bypass is advised during the time required to repair the coarctation. In addition, somatosensory evoked potentials have been measured in adults undergoing surgery for aortic aneurysm or coarctation. This involves electrical stimulation over the peroneal nerve with cephalic and lumbar responses being obtained from electrodes placed on the scalp and over the third lumbar vertebra and right iliac crest. It has been suggested that changes in these potentials can provide data that may allow the surgeon to alter the operation to prevent postoperative neurological sequelae related to spinal cord ischaemia. ${ }^{9}$

The immediate consequences of spinal cord ischaemia are flaccid paraplegia and bladder dysfunction. Pain and temperature sense are either diminished or absent while posterior column sensation may be preserved. During the acute phase we have tended to adopt an 'expectant' approach. There does not seem to be an indication for invasive investigation such as myelography or arteriography which could theoretically compound the injury.

In time, legs and bladder become spastic; there may be some recovery of power in the legs and improvement in bladder function. Sensory loss recovers most rapidly. The long term imbalance between muscular forces acting on the spine and hips may produce scoliosis and dislocation. Special attention must be given to preventing urinary infection and bladder catheterisation and prophylactic antibiotics may be indicated. Physiotherapy can help prevent muscle wasting and contractures; orthopaedic supervision is helpful in view of the likelihood that spasticity, scoliosis, and hip subluxation will be encountered. The overall prognosis for functional recovery in our experience seems to be poor, but it is very variable and difficult to predict on the basis of signs in the early postoperative period.

\section{Conclusion}

Spinal cord damage is a predictable risk in resecting 
a coarctation of the aorta and techniques to minimise this possibility have been devised. The risk does not seem related to the length of time of aortic cross clamping or to the number of collateral vessels divided. ${ }^{4}$ Perfusion pressure in the distal aorta should therefore be monitored and maintained by partial left heart bypass if it falls appreciably after cross clamping. ${ }^{8}$ This method is now practiced in Birmingham and many other centres for cardiothoracic surgery. It should be pointed out that only three of our eight patients were operated on for coarctation and this review therefore highlights the fact that children undergoing surgery for other heart conditions are unpredictably at risk of developing a spinal cord lesion. The outlook for full or partial recovery may be poor. Cord damage is a devastating event with life long implications for the child and parents. Physical as well as emotional adaptation is a slow process and may be facilitated by early referral to a spinal injuries unit where there is broad experience of such complex problems.

We thank the cardiologists and cardio-thoracic surgeons of the Birmingham Children's Hospital for permission to include their patients in this study.

\section{References}

1 Gowers WR, Taylor JA. Manual of diseases of the nervous system. 3rd ed. London: Churchill, 1889:377.

2 Tyler HR, Clark DB. Incidence of neurological complications in congenital heart disease. Archives of Neurology and Psychiatry 1957;77:17-22.

3 Tyler HR, Clark DB. Cerebrovascular accidents in patients with congenital heart disease. Archives of Neurology and Psychiatry 1957;77:483-9.

4 Brewer LA, Fosburg RG, Mulder GA, Verska JJ. Spinal cord complications following surgery for coarctation of the aorta. $J$ Thorac Cardiovasc Surg 1972;64:368-81.

5 Anonymous. Occlusion of anterior spinal artery. [Editorial]. Lancet 1958;ii:515.

6 Aguilar MJ, Gerbode F, Hill JD. Neuropathologic complications of cardiac surgery. J Thorac Cardiovasc Surg 1971;61: 676-85.

${ }^{7}$ Brennan RW, Patterson RH, Kessler J. Cerebral blood flow and metabolism during cardiopulmonary bypass: evidence of microembolic encephalopathy. Neurology 1971;21:665-72.

${ }^{8}$ Hughes RK, Reemtsma K. Correction of coarctation of the aorta: manometric determination of safety during occlusion. $J$ Thorac Cardiovasc Surg 1971;62:31-3.

${ }^{9}$ Mizrahi E, Crawford ES. Somatosensory evoked potentials during reversible spinal cord ischaemia in man. Electroencephalogr Clin Neurophysiol 1984;58:120-6.

Correspondence to Dr S H Green, Institute of Child Health, University of Birmingham, Francis Road, Birmingham B16 8ET.

Received 4 February 1985 